\title{
ANPEPP: Symposia, Research, and Postgraduate Studies from 1988 to $2014^{1}$
}

\author{
ANPEPP: Simpósio, Pesquisa e Pós-Graduação de 1988 a 2014
}

\author{
Analúcia D. Schliemann \\ Tufts University, Medford, MA, United States
}

\begin{abstract}
This article briefly describes (a) how ANPEPP was started and its first few years of activities, (b) the planning, implementation, evaluation, and recommendations by participants in the first symposium that led to future symposia format, and (c) ANPEPP's evolving activities from 1988 to 2014, taking one of its working groups (grupos de trabalho [GTs]) as an example. The analysis suggests that ANPEPP is playing a vital role in promoting fruitful interactions among researchers, contributing to a broad research agenda, and building a rich database of psychological knowledge in Brazil. Keywords: ANPEPP, history of ANPEPP, history of psychology in Brazil, GTs, postgraduate studies in psychology.
\end{abstract}

\section{Resumo}

Este artigo descreve brevemente (a) os inícios da ANPEPP e seus primeiros anos de atividades, (b) o planejamento, implementação, avaliação e recomendações dos participantes do seu primeiro simpósio que traçaram o formato dos simpósios futuros, e (c) o desenvolvimento das atividades da ANPEPP de 1988 a 2014, tomando como exemplo, o percurso de um grupo de trabalho (GT). A análise sugere que a ANPEPP está desempenhando um papel vital na promoção de interações frutuosas entre pesquisadores de psicologia, e construindo uma rica base de dados sobre o conhecimento desenvolvido pela pesquisa em psicologia no Brasil.

Palavras-chave: ANPEPP, história da ANPEPP, história da psicologia no Brasil, GTs, Pós-Graduação em Psicologia.

I was fortunate to be deeply involved in the creation of the National Association for Research and Post-Graduate Studies in Psychology, our ANPEPP (Associação Nacional de Pesquisa e Pós-Graduação em Psicologia), and in the organization, in 1988, of its first symposium. I was therefore extremely happy to attend this XV Symposium, organized by one of my first students in psychology, William Gomes, currently president of ANPEPP. I thank William and Adriane Arteche, who so carefully made the arrangements that allowed me to meet, in 2014, so many friends that I hadn't seen for such a long time and to reflect upon the development, over a quarter of a century, of ANPEPP and its symposia. We shall begin first with some history.

The creation of multiple associations of researchers and postgraduate programs in different areas was an initiative of CAPES and CNPq officers, in conjunction with their evaluation and advising committees. According to Guedes (2002), and based on an interview with Marcos Formiga, these organizations were

Correspondence concerning this article should be addressed to Analúcia D. Schliemann, Department of Education, Paige Hall, Tufts University, Medford, MA 02155, US; e-mail: ana.schliemann@tufts.edu

Inaugural keynote address at ANPEPP XV Symposium, May 6-9, 2014, Bento Gonçalves, RS, Brazil. concerned about the state of Human and Social Sciences in Brazil. ANPEPP evolved from these concerns. In the 1980s, Formiga, first at CAPES and later at CNPq, played a central role in this process. It was he, after all, who invited Carolina Bori, then coordinating CNPq's advising committee for psychology, to plan and implement the association. Carolina was joined by Aroldo Rodrigues, coordinator of the CAPES course evaluation committee at the time; by members of both committees, including me; and by other researchers in postgraduate programs in psychology. Over a number of meetings, this nucleus developed the proposal for the association, including its organizational structure and bylaws. This culminated with ANPEPP's launch during the 1983 meeting of the Brazilian Society for the Advancement of Science (SBPC - Sociedade Brasileira para o Progresso da Ciência).

ANPEPP began slowly and humbly. In its first few years, its principal activities consisted of hosting meetings for the coordinators of Brazil's postgraduate programs in psychology. In these meetings the group examined the results of CAPES program evaluations and nominated members for advising committees. They also discussed options for improvement within each program, taking into 
account the specific goals and methods of the multiple sub-areas in psychology.

One may think of CAPES evaluations as report cards that would influence the distribution of financial aid to programs in the form of student scholarships and research support. Many ANPEPP members expressed concern about the nearly exclusive reliance on quantitative indices in the program evaluations. It is fair to say that there was little to no in-depth analysis of the content, quality, and relevance of the research being produced in different areas. We were also concerned about the lack of interaction among programs with similar areas of interest.

Such concerns ultimately led to a proposal by the CNPq advising committee, then formed by Tim Mulholland, Terezinha Nunes, and Angela Biaggio, for a research symposium to be organized by ANPEPP. The symposium, to be funded by $\mathrm{CNPq}$, would showcase research from the different concentration areas of the existing programs of postgraduate studies in psychology. At the symposium, we would begin to discuss more broadly the content, quality, and relevance of the postgraduate research across programs with the aim of promoting interaction and collaboration among researchers.

\section{The First Symposium-1988}

Aroldo Rodrigues, then president of ANPEPP, and Terezinha Nunes, then coordinator of the Master's Program in Cognitive Psychology at UFPE (Universidade Federal de Pernambuco), shared the vision for the proposal suggested by CNPq. They invited me to organize ANPEPP's first symposium in Pernambuco. Jorge Falcão and other researchers, students, and staff in our program joined me in this undertaking.

The organizing committee invited the 13 existing postgraduate programs to nominate three of their researchers to participate in the meeting and to present, in plenary sessions, an overview of their research from the last five years. The programs listed 25 areas of concentration and there was considerable overlap, at least in principle, among the areas of work. Each presentation was to be 30 minutes long, followed by 10 minutes for discussion. Forty-three researchers, representing 20 areas of concentration, participated in the meeting.

In March, 1988, the First Symposium of Research and Scientific Exchange was staged at Caruaru. Lying at the heart of Pernambuco, the city of Caruaru offered suitable convention setting as well as a peaceful glimpse of daily life and culture in the northeast of Brazil.

Over the course of four days participants presented 43 plenary reports about the research work of the postgraduate programs. Between sessions, there were many opportunities for informal discussions. It was not all work, however. Attendees sampled culinary dishes typical of Northeastern Brazil, attended a play on the Passion of Christ at the open-air theatre in Fazenda Nova, and browsed stalls at the Caruaru street market.

The meeting provided a general overview of current research (see evaluation report by Camino \& Schliemann, 1988), with approximately one-fourth of the presentations describing established lines of research. Discussion topics ranged from research methods, preparation of researchers (as opposed to practitioners), cognitive versus behaviorist approaches, and individual versus socio-cultural perspectives to psychology. A number of presentations defended theoretical, ideological, or methodological positions, as opposed to presenting findings on specific lines of research. Over the course of the symposium participants expressed awareness of the lack of interaction across programs and the absence of methodological integration. Participants also noted the need for studies that took into account Brazil's specific characteristics and problems, instead of just following research trends from other countries.

The discussions during the first symposium gave rise to a series of recommendations for the future. Among these were the formation of working groups based on specific themes; farther reaching plenary presentations; and panels featuring topics of a more general interest. These recommendations were implemented in ANPEPP's second symposium. This symposium was organized by Claudio Hutz, colleagues, and students from the UFRGS program, in Gramado, RS.

\section{From the First to the Fifteenth Symposium}

From 1988 to 2014, the ANPEPP symposia grew rapidly, reflecting the expanding network of research and postgraduate studies in psychology. Today, there are many signs that ANPEPP has developed into a solid professional organization. This growth can be gleaned from even a cursory glance at the printed materials from the First and from the XV Symposium (see Figures 1 and 2). ANPEPP has also developed a highly informative website (http://www.anpepp.org.br), as depicted in its home page in Figure 3.

In 2014, ANPEPP's XV Symposium offered presentations in 68 working groups along with five plenary individual or panel presentations. There were more than one thousand attendees, researchers and students from 72 programs affiliated with ANPEPP. The organization has come a long way.

It would be beyond the scope of this paper to describe how each sub-area and working group developed over the years. Fortunately, Seidl de Moura (2002) has already provided an insightful account of how, in the first thirteen years of ANPEPP, these working groups evolved and contributed to a better integration among research groups in different areas. As an example, I will share how my research has evolved since 1988 through activities in the working group related to my field: the Psychology of Mathematics Education. 

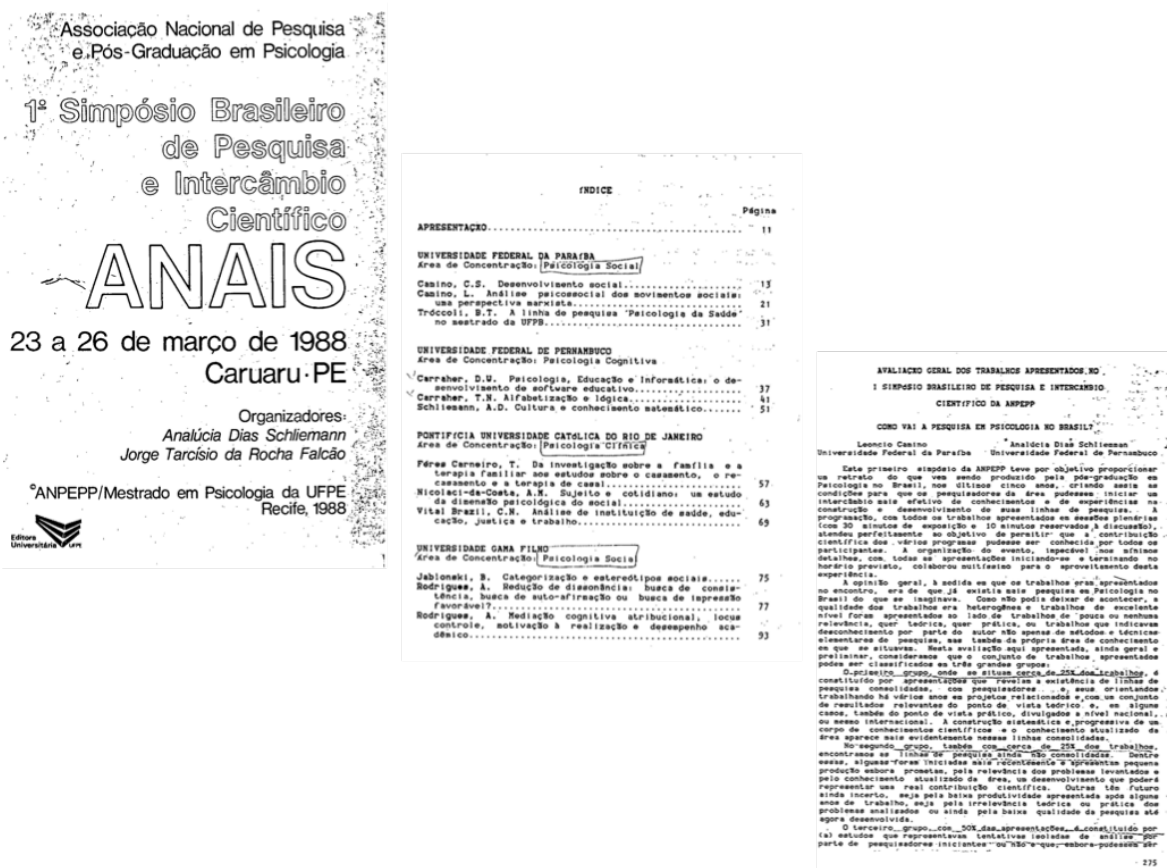

Figure 1. Cover page, index, and chapter from proceedings of ANPEPP's First Symposium.
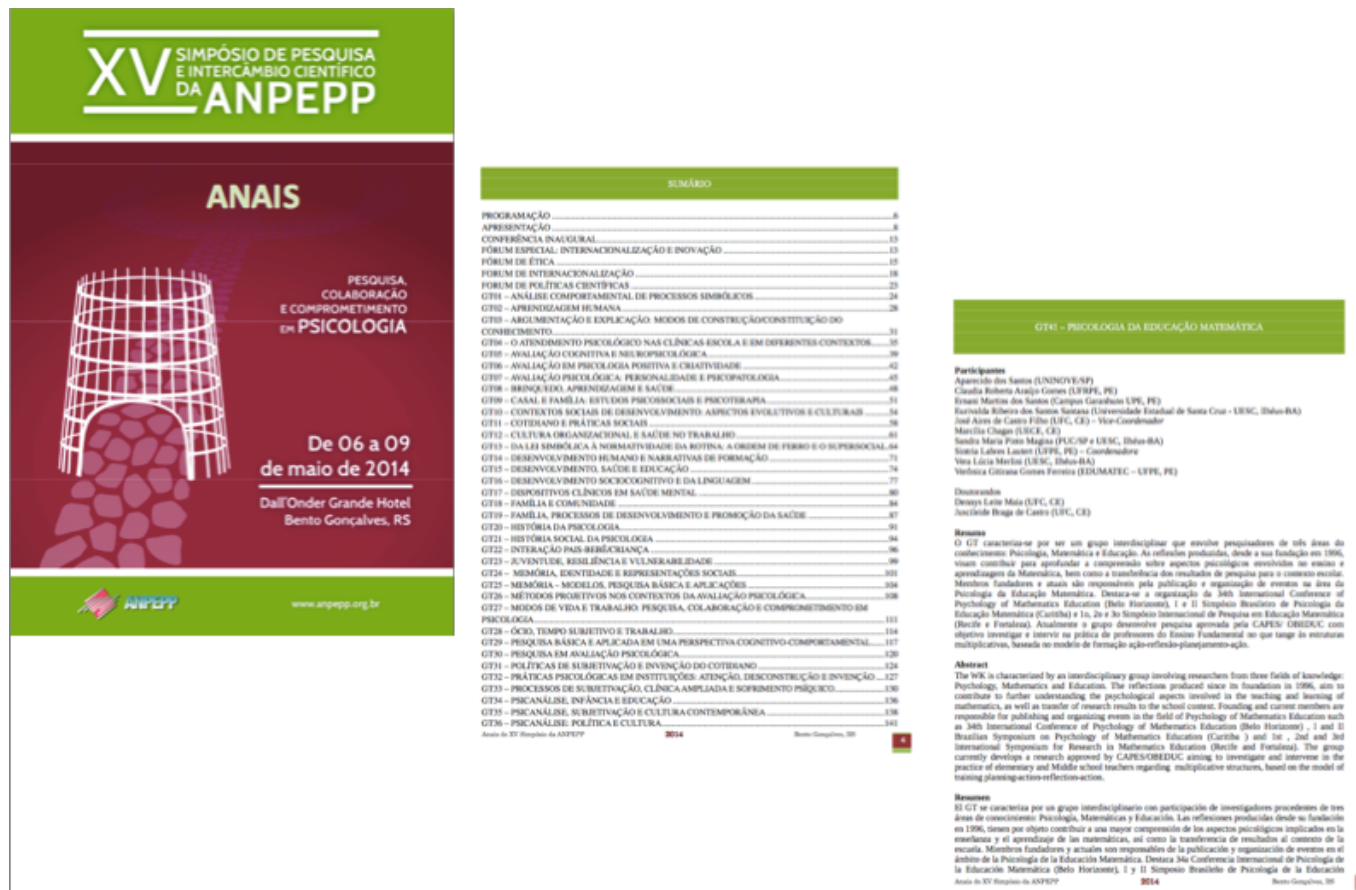

Figure 2. Cover page, index, and chapter from the proceedings of ANPEPP's XV Symposium.

\section{The Working Group on the Psychology of Mathematics Education}

In ANPEPP's first symposium a number of studies on the Psychology of Mathematics Education were reported as part of research threads on cognitive development and learning, culture and cognition, and the development of educational software. The software, for the most part, had been developed by researchers and students in the UFPE program. After that, several researchers in the area participated in different working groups. The working group on the Psychology of Mathematics Education evolved in 1996, during the VI Symposium of ANPEPP, with researchers from the program at UFPE and three other universities. 

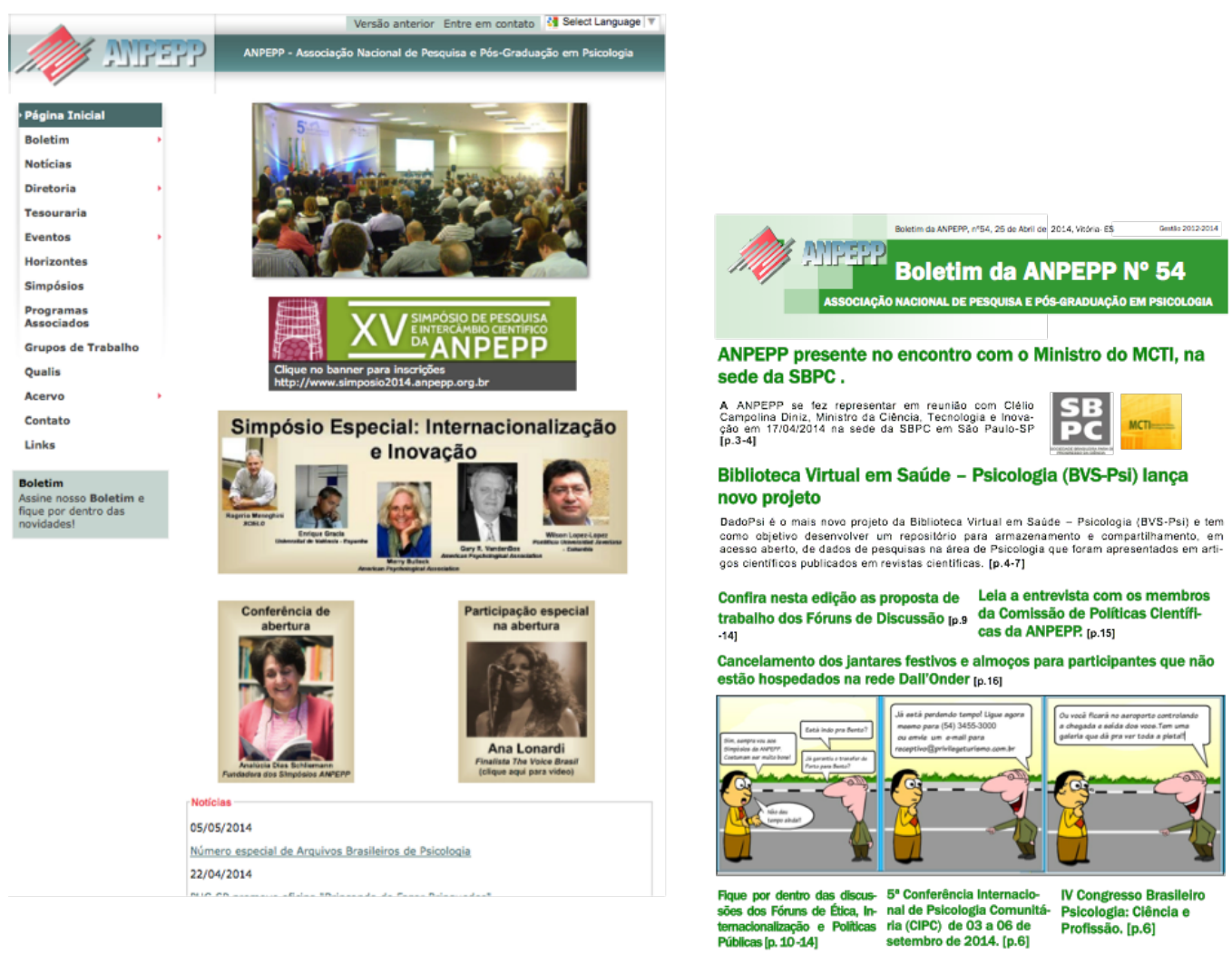

Figure 3. Pages from ANPEPP's site: http://www.anpepp.org.br

As an interdisciplinary area, the Psychology of Mathematics Education engages psychologists, educators, and mathematicians. It aims to further knowledge of mathematical concepts in different contexts and clarify the role of psychological, educational, and content factors in the construction of mathematical knowledge.

At its onset, interaction within the working group revolved around the work of the individual researcher and dealt with the understanding of arithmetic operations, place value, probability, algebra, and mathematical representations. This individualistic approach soon gave way to a collectivist ideal, in which collaboration became a core value of the group.

In 2002, researchers from eight different programs participated in the working group and were involved in joint data collection on teachers' attitudes towards mathematics, and the planning of joint publications. The group has participated in most symposia since 2002. In 2014, participants in the working group in the XV Symposium, in Bento Gonçalves, RS, came from eight different programs across six states, with researchers and doctoral students contributing to the meetings and research activities. These researchers and students are extremely active in their programs, both in the roles of scholars and educators. They play a clear leadership role in the mathematics education community. They do this through publishing the results of their studies in Brazil and abroad, as well as participating in and organizing national and international conferences. As part of the activities of the working group, researchers are currently developing an inter-state investigation into students' understanding of the conceptual field of multiplicative structures (Vergnaud, 1983, 2009). This work promises to make important contributions to the understanding of students' difficulties and strengths, in an area that relates to a large number of topics in the school curriculum. These topics range from multiplication to fractions, and include ratio, proportion, and linear functions.

\section{In Summary}

There is much to suggest that ANPEPP, in great part through its working groups and symposia, has played a vital role in promoting fruitful interactions among researchers in psychology. There is much to suggest, as well, that these interactions have contributed to the development of a broad research agenda and to the successful preparation of researchers. Additionally, ANPEPP makes the abstracts and reports of the different groups accessible online. Through this, ANPEPP is developing and caretaking a rich database on the evolving knowledge unearthed by psychologists conducting research in $21^{\text {st }}$ century Brazil. 


\section{References}

Camino, L., \& Schliemann, A. D. (1988). Avaliação [Evaluation]. In A. D. Schliemann \& J. T. da R. Falcão (Eds.), Anais do I Simpósio Brasileiro de Pesquisa e Intercâmbio Científico da ANPEPP. Dissertação de mestrado, Universidade Federal de Pernambuco, Recife, PE, Brasil. Retrieved from http://www. infocien.org/Interface/Simpos/An01T45.pdf

Guedes, M. C. (2002). Para uma história da ANPEPP. Entrevista com Marcos Formiga [For a history of ANEPP: Interview with Marcos Formiga]. Retrieved from http://www.anpepp.org.br/ old/1-Acervo/B-historico/hist_anpepp.htm

Seidl de Moura, M. L. (2002). Treze anos de grupos de trabalho nos simpósios da ANPEPP: Algumas tendências e evidências de promoção de maior integração [13th year of working groups in the Symposia of ANPEPP, trends and evidences] Associação Nacional de Pesquisa e Pós-Graduação em Psicologia (Ed.). Anais do IX Simpósio de Pesquisa e Intercâmbio Científico da ANPEPP, 19-28.

Vergnaud, G. (1983). Multiplicative structures. In R. A. Lesh \& M. Landau (Eds.), Acquisition of mathematics concepts and processes (pp. 127-174). New York: Academic Press.

Vergnaud, G. (2009). The theory of conceptual fields. Human Development, 52, 83-94. 